REDES- Revista hispana para el análisis de redes sociales

Vol.24,\#2, Diciembre 2013

http://revista-redes.rediris.es

\title{
Diario de campo
}

Daniel Holgado Ramos

Departamento de Psicología Social, Universidad de Sevilla ${ }^{\mathbf{1}}$

\section{Reseña:}

Izquierdo Chaparro, R. (2013). Diario de Campo. Barcelona: Caballo de Troya.141 pág.

"La ciencia social clásica ha dotado a la distancia de una virtud excesiva, y a la cercanía de un vicio excesivo". Esta frase de Renato Rosaldo, antropólogo social, sirve para ilustrar perfectamente el espíritu y la orientación del ensayo, novela o experimento etnográfico (o todo a la vez) de Rosario Izquierdo: "Diario de Campo". Porque de eso se trata. De cómo una investigadora social se encuentra inmersa en un contexto social objeto de diagnóstico. Y de cómo la propia historia personal y profesional, el contacto con las personas de ese contexto, modulan las reflexiones y conclusiones que se pueden extraer. La autora muestra cómo ser consciente del modo en que los propios los valores influyen en el trabajo de campo, la extracción de información y la reflexión sobre la misma, puede suponer una ventaja al enfrentarse a la investigación social.

Hablaba también Renato Rosaldo de la "heroicidad de la investigación libre de valores", reflexionando sobre el sentido de la objetividad de Webber en la investigación social y de su idea de tratar de aclarar el mundo antes que cambiarlo. Pero desde nuestro punto de vista, y parafraseando a Kurt Lewin, cambiar el mundo implica comprenderlo. Rosario Izquierdo hace algo parecido. Adopta una posición comprometida con el contexto de análisis, hace suyas las dificultades y los problemas que observa, los integra y los vincula a sus vivencias personales. Pero en ese mismo contexto, también trata de comprender los fenómenos sociales que observa, se esfuerza por aplicar herramientas metodológicas innovadoras (como el ARS) y, sobre todo, por utilizar los resultados de la investigación para solucionar los problemas de las personas (objetos y sujetos de investigación e intervención).

${ }^{1}$ Contacto: Daniel Holgado Ramos, Departamento de Psicología Social, Universidad de Sevilla, 41018, Sevilla, España. Dirección Electrónica: daniel.holgado@gmail.com 
Porque, como también apuntaba Lewin, la investigación social no tiene sentido sin la acción social y viceversa. La autora, a través de su relato, se convierte en un ejemplo claro del papel que desde estos postulados y las corrientes más recientes de la Psicología Comunitaria provenientes de autores como Zimmerman, Rappaport, Sarason o Wandersman, se establece para el investigador e interventor social. El investigador social debe proporcionar herramientas de cambio al entorno comunitario y, como interventor, debe redefinir su rol para ser un promotor de dicho cambio, un colaborador de la comunidad, en definitiva.

La estructura de "Diario de Campo" combina estractos del diario de campo de la autora al que alude el título, con la reflexión sobre el contexto y el encuentro con sus habitantes. Estos habitantes son las mujeres del barrio y también lo vemos a través de sus ojos y de sus relatos personales.

El libro se divide en cuatro secciones. La primera sección, "Entrevista número seis" describe por un lado su primer contacto con el barrio y añade una caracterización valiosa e interesante del contexto físico y social del mismo. Por otro lado, cabe destacar la inmersión en el proceso de entrevista con una mujer y en el intercambio que se produce entre la entrevistadora y la entrevistada. La segunda, "Burkas", gira en torno a la experiencia y la reflexión de la autora a partir del encuentro fortuito con una mujer vestida con esta prenda. En la cuarta y última sección "Entrevista número dos", la autora establece un paralelismo entre su propia vida y su acceso al mercado laboral con la de aquellas mujeres que ha entrevistado en su trabajo en el barrio.

Nos detendremos con más detalle en la sección tres, "Redes", por ser la más cercana a los objetivos de esta revista. En este capítulo, la autora hace referencia a la importancia de las redes personales de las jóvenes con los que trabaja en la búsqueda de oportunidades laborales y el acceso al empleo. La redundancia de los lazos fuertes en los grupos sociales, la ausencia de lazos débiles que permitan acceder a otros espacios sociales y encontrar información nueva (Granovetter, 1973) "tiran de las jóvenes manteniéndolas ancladas en los barrios" (p. 83).

Cabe destacar cómo se describe el proceso de evaluación de estas redes, desde la planificación inicial (con las dificultades para justificar su idoneidad para el trabajo con jóvenes en riesgo de exclusión social ante otros profesionales) hasta las estrategias para vencer la resistencias de los hombres y mujeres entrevistados. Ello añade un valor importante al libro, al mostrar elementos del proceso que suelen quedar fuera de los productos de investigación y que pueden ser de utilidad para 
conocer las barreras, las dificultades y el coste en recursos personales que supone la investigación social.

Por otro lado, también es interesante el papel otorgado a la visualización y el feedback en el análisis de las redes personales. En este caso la reacción de los entrevistados ante el grafo aporta información importante sobre la red personal de apoyo. Más allá de esta reacción inicial, las representaciones de las redes son utilizadas por la autora como un punto para continuar con la evaluación y el diagnóstico social sobre aspectos como las expectativas de empleo y otras esferas de la vida personal. Incluso suponen un elemento de motivación para las entrevistadas, una especie de acicate para romper la resistencia natural a este tipo de evaluaciones. La ejemplificación con casos reales añade un valor adicional a este proceso.

En resumen, "Diario de campo" es una lectura interesante para comprender ese proceso de inmersión social y de contacto con el contexto de investigación y de cómo la interacción con los valores personales y profesionales afectan a dicho proceso y a la propia construcción de la identidad del investigador.

\section{Referencias bibliográficas}

Granovetter, M. (1973). The Strength of Weak Ties. The American Journal of Sociology, 78(6), 1360-1380. 